\title{
frontiers
}

FOR YOUNG MINDS

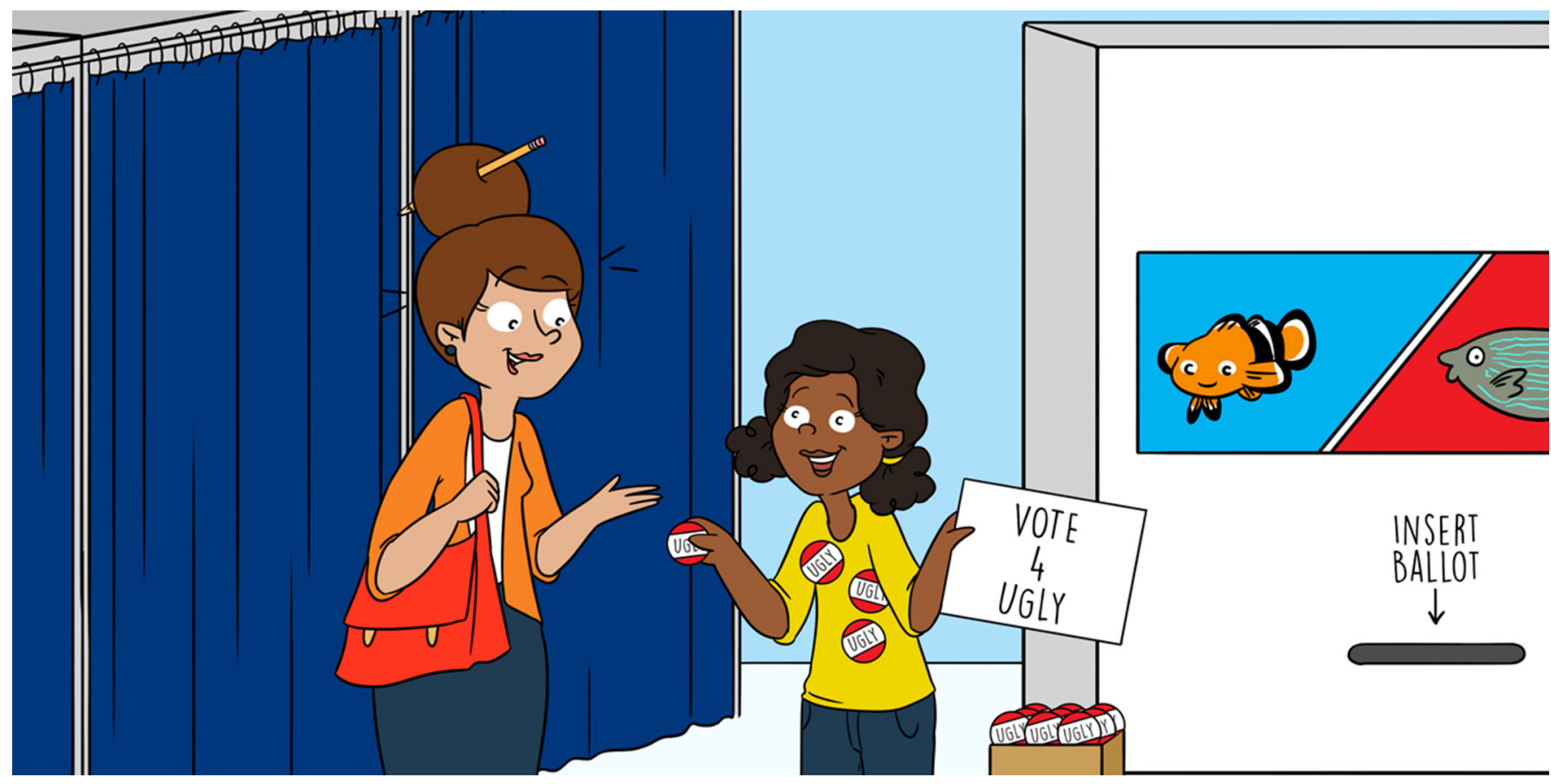

\section{CORAL REEF FISH: NOT JUST A MATTER OF BEAUTY!}

Elyse Boudin ${ }^{1 *}$, Frédérique Carcaillet ${ }^{1 *}$, Anne-Sophie Tribot ${ }^{1 *}$, Quentin Carabeux ${ }^{1}$, Julie Deter ${ }^{1,2,3}$, Thomas Claverie ${ }^{1,4}$, Sébastien Villéger ${ }^{1}$ and Nicolas Mouquet ${ }^{1,3^{*}}$

${ }^{1}$ MARBEC, CNRS, Ifremer, IRD, University of Montpellier, Montpellier, France

${ }^{2}$ Andromède Océanologie, Carnon, France

${ }^{3}$ Common Laboratory InToSea, Andromède Océanologie, Université de Montpellier, Montpellier, France

${ }^{4}$ Centre Universitaire de Formation et de Recherche de Mayotte, Dembeni, Mayotte

YOUNG REVIEWERS:

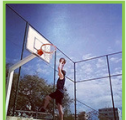

GUSTAVO

AGE: 14

HABIBA

AGE: 12

SELENA

AGE: 12
Coral reefs are vulnerable ecosystems where a great number of fish species live. Some fish are beautiful, and some are not. This study compared the human perception of fish beauty with the ecological roles and characteristics of these fishes. It appears that ugly fish have a wider variety of roles in the coral reef ecosystem than beautiful fish do. This means that the ugly fish seem to be more important for ecosystems. The results of this study warn us about the need to preserve not just cute fishes, but the entire ecosystem, which means protecting the ugly fish as well as the beautiful ones.

\section{BIODIVERSITY AND CORAL REEFS}

In the scientific study of animals, we often talk about biodiversity. But what does that mean? Biodiversity refers to the diversity, or different kinds of living beings, in a certain habitat or ecosystem. You can get a glimpse of biodiversity when you walk around, by observing the 
Figure 1

Online survey to determine which fish people find more beautiful. On each screen, two fish species appeared and the survey participants had to choose the one they thought was more beautiful. On the left is a clownfish (Amphiprion latifasciatus) and on the right is a young green birdmouth wrasse (Gomphosus caeruleus). In this example, the participant found the clownfish more beautiful (fish pictures: Randall, J. E. from FishBase.org).

\section{ECOSYSTEM}

A community of species living together in a specific place and interacting with each other and the environment.

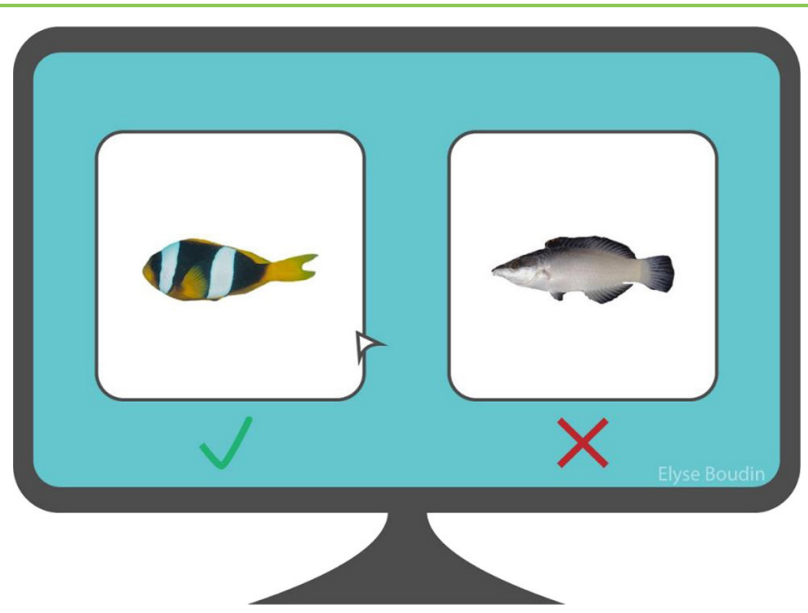

Figure 1

different colors, shapes, and sizes of plants, animals, and fungi that are around you. But you can also see biodiversity by observing the immense Amazonian forest in South America, or the Great Barrier Reef in the sea off Australia. Both of these ecosystems support life, but they do not function in the same way. You would not find the same species or the same temperatures in the rainforest as you will in a coral reef. On land and in the sea, there is a great diversity of ecosystems.

Coral reefs are important ecosystems where up to 8,000 species of fish live. These reefs provide many services to humans. For instance, they protect shores against large waves and provide fish for humans to eat. The reefs are also simply beautiful, and that is why many divers admire them.

\section{UGLY FISH vs. BEAUTIFUL FISH}

You probably know Nemo, the orange and white clownfish (Amphiprion percula) hero of the movie "Finding Nemo" and his friend Dory, a blue and yellow surgeonfish (Paracanthurus hepatus). These fish species do actually live in coral reefs and are sought after for their beauty. It is this beauty that ecology researchers have been interested in. These researchers wondered whether the fish that humans appreciate the most and find the most beautiful were as useful to the coral reef ecosystem, as the ugly fishes that humans less appreciate. How did these researchers first determine which fish people found beautiful? They conducted an online survey with photos of tropical fish. Each page had two photos and the survey participant had to click on the most beautiful fish (Figure 1). Eight thousand people did the online test, with 20 different comparisons each. A total of 116 fish species were ranked from the ugliest to the most beautiful, according to the number of votes received from the survey. 
Figure 2

How does the beauty of fish relate to their roles in the ecosystem? The group of fish with fewer votes, or the "ugly" fish, have a greater diversity of ecological characteristics. On the other hand, the "beautiful" fish that received more votes have fewer ecological characteristics. This means that the "uglier" fish are actually more useful for the functioning of coral reefs (pictures from left to right: tubelip wrasse (Labrichtys unilineatus), bluefin trevally (Caranx melampygus), moon wrasse (Thalassoma lunare), sea goldie (Pseudanthias squamipinnis), raccoon butterflyfish (Chateodon lunula), and semicircle angelfish (Pomacanthus semicirculatus) (source: Randall, J. E. from FishBase.org).

\section{ECOLOGICAL}

\section{CHARACTERISTICS}

Characteristics that define the life of a species in its environment: its diet, its reproduction, its swimming speed, its habitat preferences, etc.

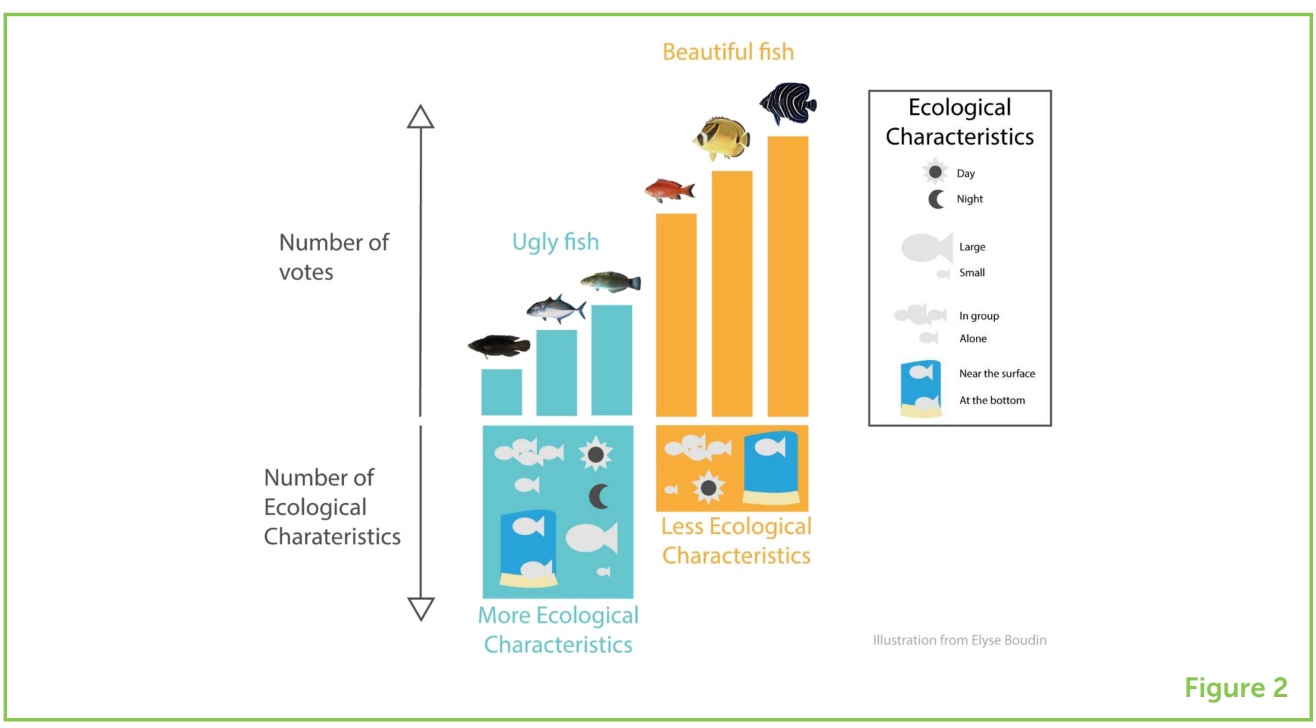

The results of the survey showed that Nemo and Dory are in the group of the prettiest fish, but not at the top. The most attractive fish, according to the survey, is the semicircle angelfish (Pomacanthus semicirculatus), a black and white fish, and the least attractive is the tubelip wrasse (Labrichtys unilineatus) a brown fish (see Figure 2). It appears that people prefer round fish that have patterns on the body like stripes, or fish with lots of different colors. In short, people prefer fish that are easy to notice!

\section{THE ROLES OF FISH IN CORAL REEFS}

Researchers then turned their attention to the roles of fish in the coral reef ecosystem. Fish have different physical and ecological characteristics. Ecological characteristics of a species are the characteristics that define the life of a species in its environment: its alimentation, its reproduction, its swim speed, its habitat... They do not all eat the same thing, they can be large or small, they can swim in a group or alone, swim either near the surface or toward the bottom, they can move continuously or remain still, and they can be active during the day or the night. The fewer characteristics fish have in common, the more likely the roles they play in the coral reef will be different from each other. These different ecological roles can also be called complementary roles, meaning they all work together to keep the reef healthy. For example, the moray eel, a fish that is a bit like a snake, hunts fish, crabs, and octopuses in coral reefs. As it swims between the corals, the moray eel tears away the algae that grow on it. When cleaned, the corals breathe better. It is because of the moray eel's shape that it can do this-other fish could not swim between the corals as easily. Fish with different behaviors will not eat the same thing, either. A fish that lives on the bottom will eat worms or shellfish hidden in the sand, while a fish that lives near the surface will more likely eat other small fish. 


\section{Figure 3}

Beautiful coral fish species can be flagship species, which attract more research and money away from other, less attractive fish species that are important for keeping coral reef ecosystems healthy. The top panel represents a healthy coral reef ecosystem with both ugly and beautiful fish. The bottom panel shows that, if they are not taken care of, the ugly fish disappear and the ecosystem will not function properly (source: Randall, J. E. from FishBase.org).
Researchers were interested in the ecological characteristics of each fish to determine their roles in the ecosystem. The researchers then looked at the number of different ecological characteristics between ugly fish and beautiful fish. By comparing the ecological characteristics of these fish, they realized that beautiful fish share many ecological characteristics, and therefore have very similar roles in the ecosystem. This is not the case for ugly fish, which have many different ecological characteristics, some of which are shared by beautiful fish (Figure 2). The researchers found that ugly fish have many different ecological roles, so they are probably more useful for the functioning of coral reefs!

\section{A PROBLEM FOR THE PROTECTION OF SPECIES}

Coral reefs are useful to humans, but they are also very fragile ecosystems. Coral reefs are currently disappearing from the oceans due to climate change, pollution, and intensive fishing. To reduce these threats to coral reefs, we need to be better educated about the

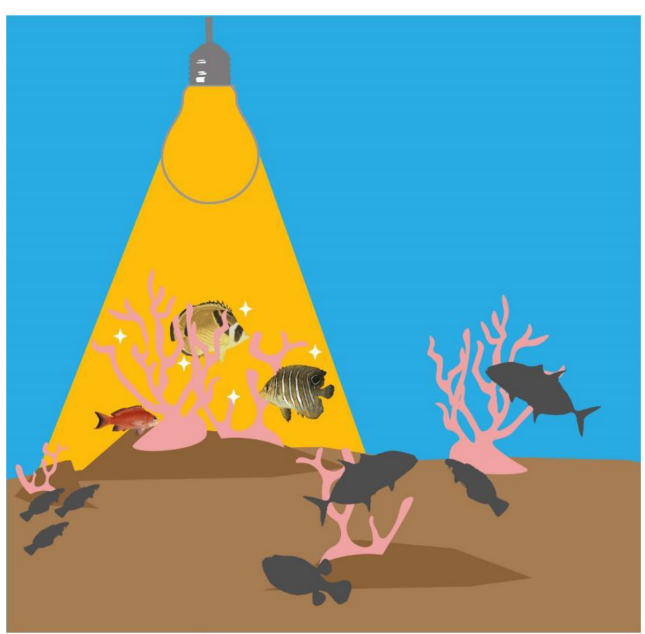

\section{Flagship species}

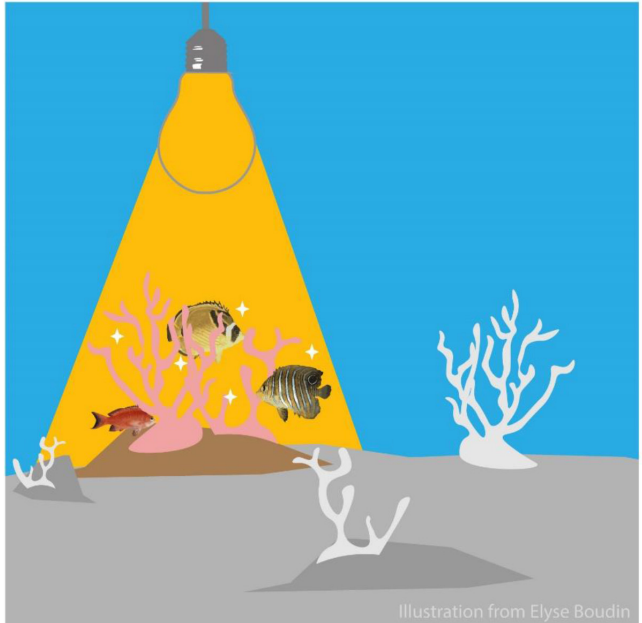

\section{The other} species

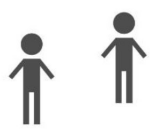

Less Research

$$
\$
$$

Less money 


\section{FLAGSHIP SPECIES}

Well-known endangered species that people want to save and often donate money for, like the giant panda. diversity of roles different fish play and how these roles are important for healthy coral reef ecosystems.

But there is a problem. Humans like to protect what we find beautiful. Like the giant panda, for example, which is such an endearing species that it attracts a lot of money for research and its protection. This species is called flagship species, which means well-known endangered species that people want to save and often donate money for, like the giant panda. The protection of some flagship species can sometimes help with the protection of other species. For example, if money is used to restore the environments in which flagship species live, other species living in the same environment will also benefit. These flagship species act as an "umbrella": they protect other species that are less well-known but are also endangered. But sometimes, flagship species attract too much of our attention and make us forget about other important species that share the same environment but might need their own protection from threats (Figure 3).

Our appreciation for animals that are beautiful, cute, and endearing can therefore have a bad side, by keeping us from learning about other species that we may think are ugly and strange, but that are essential to the survival of other living beings on Earth, including us! In the case of coral reefs, it is clear that the fish we find the most beautiful are not necessarily the most useful for the functioning of the reef. Beautiful fish are necessary of course, but if we only kept the pretty fish, we would have a beautiful ecosystem that would not be ecologically functional. In this study, researchers helped to show us the extraordinary diversity of tropical ocean fishes, and they reminded us to appreciate fish species we might not always find pretty. This research is important because it shows us that it is only by getting to know our fishes and our planet better that we will really be able to love the earth enough to preserve it in its entirety, both pretty species and ugly species, too.

\section{ORIGINAL SOURCE ARTICLE}

Tribot, A.-S., Carabeux, Q., Deter, J., Claverie, T., Villéger, S., and Mouquet, N. 2018. Confronting species aesthetics with ecological functions in coral reef fish. Sci. Rep. 8:11733. doi: 10.1038/s41598-01 8-29637-7

SUBMITTED: 06 August 2019; ACCEPTED: 28 January 2020; PUBLISHED ONLINE: 19 February 2020.

EDITED BY: Pedro Morais, Centre of Marine Sciences, University of Algarve, Portugal 

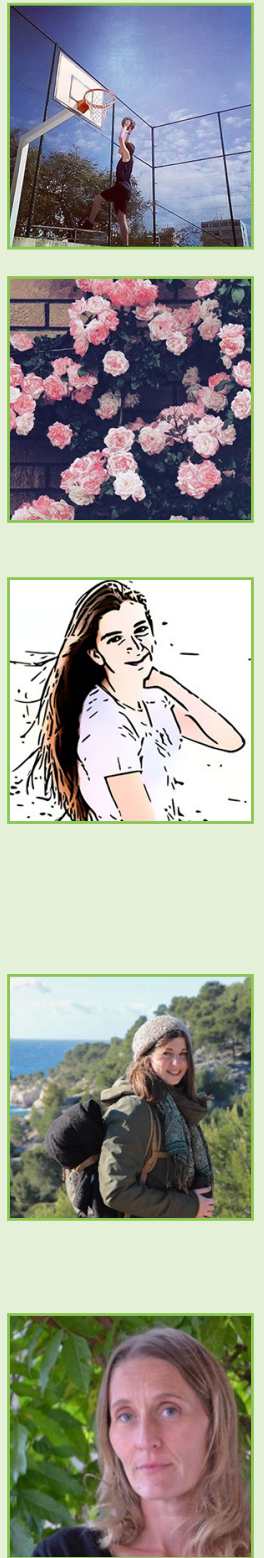

CITATION: Boudin E, Carcaillet F, Tribot A, Carabeux Q, Deter J, Claverie T, Villéger $S$ and Mouquet N (2020) Coral Reef Fish: Not Just a Matter of Beauty! Front. Young Minds 8:13. doi: 10.3389/frym.2020.00013

CONFLICT OF INTEREST: The authors declare that the research was conducted in the absence of any commercial or financial relationships that could be construed as a potential conflict of interest

COPYRIGHT @ 2020 Boudin, Carcaillet, Tribot, Carabeux, Deter, Claverie, Villéger and Mouquet. This is an open-access article distributed under the terms of the Creative Commons Attribution License (CC BY). The use, distribution or reproduction in other forums is permitted, provided the original author(s) and the copyright owner(s) are credited and that the original publication in this journal is cited, in accordance with accepted academic practice. No use, distribution or reproduction is permitted which does not comply with these terms.

\section{YOUNG REVIEWERS}

\section{GUSTAVO, AGE: 14}

$\mathrm{Hi}$, I am Gustavo, from Portugal. I love to swim, surf, play basketball, and read manga books. My mom is a marine biologist and I want to become a marine biologist myself!

\section{HABIBA, AGE: 12}

$\mathrm{Hi}$, my name is Habiba and I am 12 years old. My favorite sport is basketball and I also like badminton. I like hanging out with my friends, reading, watching movies, and visiting my home country. My favorite foods are pizza, biryani, samosa, chips, and a bunch of other foods.

\section{SELENA, AGE: 12}

$\mathrm{Hi}$, my name is Selena. I am 12 years old and my favorite sports are soccer, basketball, and volleyball. I like to do many things like reading, studying, hanging out with my friends and family, and traveling. My favorite foods are mostly from my home country. I really love participating in as many extracurricular activities as possible.

\section{AUTHORS}

\section{ELYSE BOUDIN}

Elyse Boudin is finishing a master's degree in Ecology Engineering at the University of Montpellier. This work was a part of her master's internship at the Marine Biodiversity Exploitation and Conservation Laboratory (MARBEC). She wants to work in the environment and sustainable development education field to create a bridge between researchers and young people. *elyse.boudinagmail.com

\section{FRÉDÉRIQUE CARCAILLET}

Frédérique Carcaillet is senior lecturer in Aquatic Ecology at the University of Montpellier in France, where she mainly teaches ecology and environmental science communication. Her research includes ecosystem function, science 

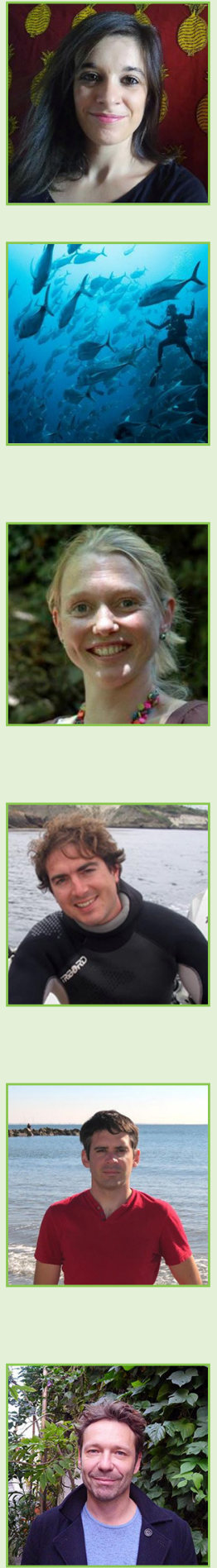

communication, and environmental education. She runs science animation film workshops to teach students how to communicate science to the general public. https://www.youtube.com/channel/UCdMXIvXqFZxiSFtsnFUQiZg/videos *frederique.carcaillet@umontpellier.fr

\section{ANNE-SOPHIE TRIBOT}

Anne-Sophie Tribot is interested in studying biodiversity and human-nature relationships. Combining ecology and sociology, her objectives are to better understand our perception of nature using statistical methods, in order to contribute to the conservation of biodiversity. *anneso.tribot@free.fr

\section{QUENTIN CARABEUX}

Quentin Carabeux is a scuba diver in tropical areas. He is using all the knowledge he is got on coral ecosystems, due to his master's degree, to teach divers the importance of this ecosystem. He is combining tourism and science to provide a double service to the customers. His wish is to reach the maximum of people in order to change their behaviors by helping them understand the knowledge of the scientists.

\section{JULIE DETER}

Julie Deter is R\&D project manager at Andromède Océanologie (a small French company) and senior lecturer at the University of Montpellier in ecology and environmental science. She is interested in the links between humans and marine biodiversity, like the impact of human activities, ecosystem services, and communication to the general public.

\section{THOMAS CLAVERIE}

Thomas Claverie is a marine biologist at the University Center of Mayotte. He is interested in the link between structure and function in a context that is both evolutionary and ecological. The animal models on which he works are mainly crustaceans and fish. Thomas works on the functioning of lagoon ecosystems and the impact of human activities on it.

\section{SÉBASTIEN VILLÉGER}

Sébastien Villéger is a senior researcher at the CNRS in Montpellier (MARBEC lab). $\mathrm{He}$ is interested in the effects of global changes, especially in exotic species, on the biodiversity of aquatic ecosystems. He has also been studying the roles organisms play in aquatic ecosystems, mostly through nutrient recycling, and the interactions between microbes and animals. http://www.umr-marbec.fr/villeger-sebastien.html

\section{NICOLAS MOUQUET}

Nicolas Mouquet is a senior researcher with the CNRS and the director of the Centre for Ecological Synthesis and Analysis of Biodiversity in Montpellier. He has been working on the relationship between diversity and ecosystem functioning. He is now interested in disentangling the factors that shape the different facets of biodiversity in marine ecosystems, ecological rarity, and the relationship between humans and nature. http://nicolasmouquet.free.fr/ *nicolas.mouquet@enrs.fr 